\title{
Partial appointment booking improves attendance for cognitive behavioural therapy
}

Kenwright M, Marks IM. Improving first attendance for cognitive behaviour therapy by a partial booking appointment method: two randomised controlled trials. J Ment Health 2003;12:385-92.

\section{Does a partial booking appointment method improve first attendance for cognitive behaviour therapy?}

\section{METHODS}

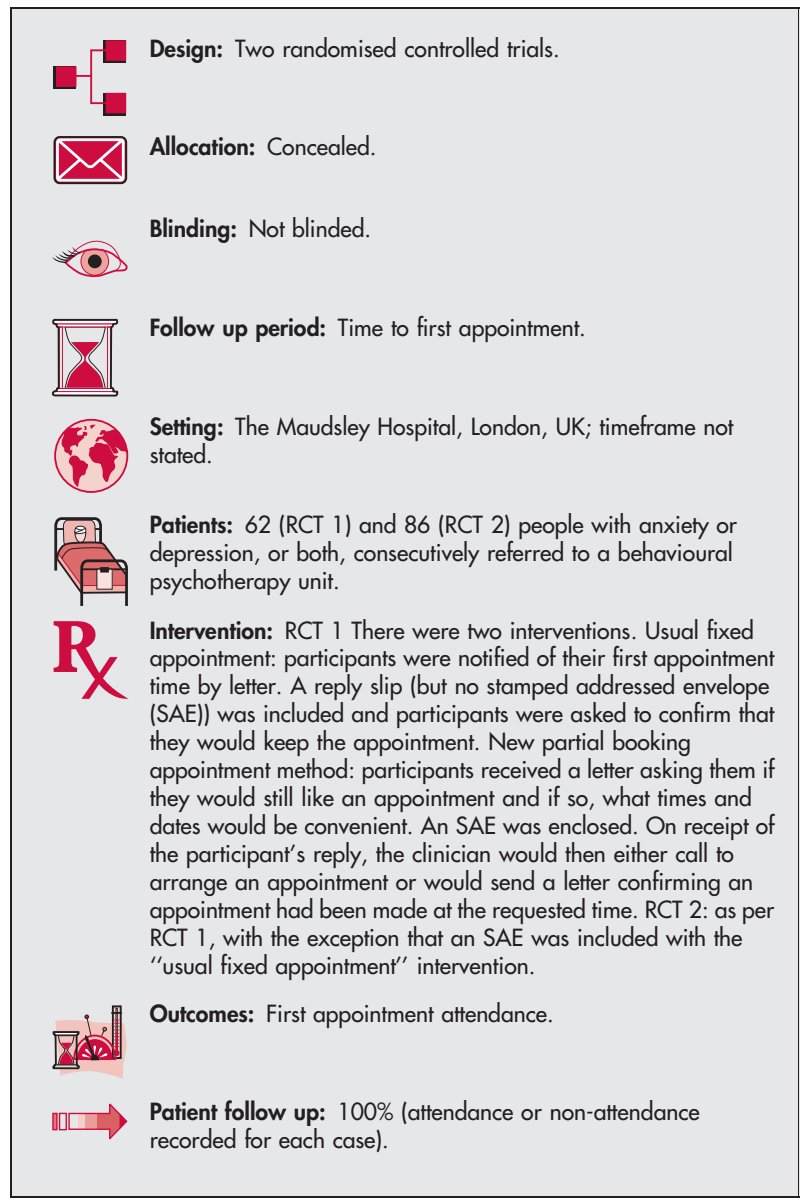

\section{MAIN RESULTS}

Significantly more people attended their first scheduled psychotherapy appointment with the partial booking method compared with the usual fixed appointment method $(\mathrm{p}<0.001$ for both RCTs; see table).

\section{CONCLUSIONS}

A participant initiated partial appointment booking method improves attendance for cognitive behaviour therapy.

For correspond Service, Avenue House, Acton, London, UK; mark.kenwright@wlmht.nhs.uk Sources of funding: not specified.
Table Attendance at first appointment

\begin{tabular}{|c|c|c|c|c|}
\hline \multirow[b]{2}{*}{ Outcome } & \multicolumn{2}{|l|}{ RCT 1} & \multicolumn{2}{|l|}{ RCT 2} \\
\hline & $\begin{array}{l}\text { Usual } \\
\text { method } \\
\text { (no SAE) } \\
(n=31)\end{array}$ & $\begin{array}{l}\text { Partial } \\
\text { booking } \\
\text { method } \\
(n=31)\end{array}$ & $\begin{array}{l}\text { Usual } \\
\text { method } \\
\text { (with SAE) } \\
\text { ( } n=42 \text { ) }\end{array}$ & $\begin{array}{l}\text { Partial } \\
\text { booking } \\
\text { method } \\
(n=44)\end{array}$ \\
\hline $\begin{array}{l}\text { First appointment } \\
\text { attendance }\end{array}$ & $\begin{array}{l}14 / 30 \\
(47 \%)\end{array}$ & $\begin{array}{l}23 / 27 \\
(85 \%)^{*}\end{array}$ & $\begin{array}{l}28 / 41 \\
(68 \%)\end{array}$ & $\begin{array}{l}35 / 39 \\
(90 \%)^{*}\end{array}$ \\
\hline $\begin{array}{l}\text { Did not attend without } \\
\text { notice }\end{array}$ & $\begin{array}{l}13 / 30 \\
(43 \%)\end{array}$ & $0 / 27$ & $\begin{array}{l}10 / 41 \\
(24 \%)\end{array}$ & $0 / 44$ \\
\hline \multicolumn{5}{|c|}{ Cancelled appointment } \\
\hline Rearranged & 2 & 0 & 2 & 4 \\
\hline Refused & 1 & 0 & 1 & 1 \\
\hline $\begin{array}{l}\text { Other (died, unfunded, } \\
\text { seen at other units) }\end{array}$ & 1 & 4 & 1 & 0 \\
\hline
\end{tabular}

*Expressed as a percentage of those participants that replied to the initial letter and for whom appointments were made.

\section{Commentary}

his study, using a randomised controlled design, evaluates the effects of a partial booking system on first appointment attendance rates in an outpatient cognitive behavioural therapy clinic. The new partial booking system was proposed by the UK Department of Health in response to the cost incurred to services through non-attendance of first appointments. It is therefore clear that the development of an alternative to the costly fixed appointment system current in most clinics is a timely subject for research. The partial booking system was found to be effective in general hospital outpatient settings but this study tests this system in a mental health setting for the first time. The study builds on previous "opt in" methods by allowing patients to request preferred appointment times.

The results of this study were positive, showing that the partial booking method was highly effective in reducing first appointment non-attendance rates in a mental health outpatient setting. Therefore this intervention should continue to be evaluated in other mental health settings throughout the UK. It should be noted that the setting was a high profile, specialist outpatient clinic and that the results may not be generalisable to routine practice settings. The intervention does require a degree of self directedness and motivation from the clients and flexibility from clinicians. It would have been interesting to have had some details on the demographics of this population group (both clients and clinicians). In $68 \%$ of cases the intervention established direct phone contact between clinician and client. This could be viewed as the start of the therapeutic process and the authors rightly note that this aspect could be a potentially confounding factor. However, there is also the possible implication that if the intervention engages clinician and client before therapy commences, the risk of dropout later on in therapy may also be reduced. It was shown in an outcome study ${ }^{1}$ that non-completers had significantly poorer outcomes with regard to clinically significant change. This intervention could therefore be invaluable in reducing the costs incurred through patients leaving therapy before they have had the optimum dose and being referred again.

Jane Cahill, MA

Psychological Therapies Research Centre, University of Leeds, UK

1 Cahill J, Barkham M, Hardy GE, et al. Outcomes of clients completing and not completing cognitive therapy for depression. Br J Clin Psychol 2003;42:133-43. 